\title{
INTRODUCTION TO NONLINEAR DYNAMICS
}

FOR PHYSICISTS 
This page is intentionally left blank 
World Scientific Lecture Notes in Physics - Vol. 53

\section{INTRODUCTION TO NONLINEAR DYNAMICS FOR PHYSICISTS}

Henry D. I. Abarbanel

M. I. Rabinovich

M. M. Sushchik

Department of Physics and Institute for Nonlinear Science University of Califomia, San Diego

La Jolla, Ca 92093-0402

USA 


\section{Published by}

World Scientific Publishing Co. Pte. Ld.

P O Box 128, Farrer Road, Singapore 9128

USA office: Suite 1B, 1060 Mrin Street, River Edse, NJ 07661

UK office: 73 Lynton Mand, Touteridge, Lowdon N20 \&DH

\section{INTRODUCTION TO NONLINEAR DYNAMICS FOR FHYSICISTS}

Copyright 01993 by World Scientific Publishing Co. Pte. Led.

All righes reserved. This boak, or parts thereof, may not be reproduced in any form or by any means, electronic or mechanical, including photocopying, reconding or any information storage and retrieval system now known or to be invented wichout writen permistion from the Publisher.

For photocopying of materials in this volume, pleave pay a copying foe through tho Copyright Clearnoce Center. Inc., 27 Congress Street, Salem, MA 01970, USA.

ISBN 981-02-1409-X

981-02-1410-3 (pbl)

Printed in Singapore by Continental Press Pte LId 


\section{Preface}

This is a series of lectures on nonlinear dynamics for physicists. The level is that of an advanced undergraduate or beginning graduate student. The assumption is made that the student has completed an advanced mechanics course and has had some exposure to mathematical physics of the sort encountered in an advanced electricity and magnetism or quantum mechanics course. No detailed knowledge of nonlinear dynamics is assumed, but familiarity with ordinary differential equations is. Some of the material is cast at a level which is more challenging to persons having only an undergraduate background in Pbysics but we felt that the subject was sufficiently interesting and rich that posing this kind of challenge was within the scope of the course. Similarly some of the material is aimed below that of a typical first year graduate student, but we also felt that this would serve both as a reminder and as a presentation of perbaps a different point of view for such students.

In any case the main goal of the lectures is to present both substantial qualitative information about phenomena in nonlinear systems to the advanced Physics student making the flavor tantalizing, yet providing sufficient quantitative material that the student would learn how to proceed in similar situations without the instructors "magic wand", which seems, we admit, to be waved here and there. Thus we set ourselves an impossible challenge overall, but we hope that the reader will find some success in our achieving these goals. Anyway, we trust enough success that we can hope for feedback from readers on topics (both those included and those left out), difficulty of presentation, and other items related to scientific material and pedagogy.

We hope that the reader, and even more the person who both hears the lectures and read these notes as they evolve to more finished stages, will have addressed three main questions about nonlinear dynamics:

- What is nonlinear dynamics all about and what makes it differ from linear dynamics which permeates all familiar textbooks? 
- From the physicist's point of view, why should we study nonlinear systems and leave the comfortable territory of linearity?

- How can one progress in the study of nonlinear systems both in the analysis of these systems when we know them and in learning about new systems from observations of their experimental behavior?

Of course, neither these lectures nor whole lifetimes of work can possibly answer all of these questions in the finest detail. Nonetheless, we have set these impossible goals so that the student will reach with us slightly beyond an easy grasp.

These lectures were originally given by M. I. Rabinovich as Physics 155 in the UCSD Physics Department during the Fall Quarter of the 1992/93 academic year. Notes were taken and then transcribed by M. M. Sushchik, and edited by H. D. I. Abarbanel. It is our plan that this course will be taught by Abarbanel in the 1993/94 academic year at UCSD, and that they will be improved based on that experience and extensive input from the students of each course. Eventually we are thinking of making these notes into a monograph/textbook, but the barriers for turning a useful pedagogical product into a polished book are known to be high.

The problems were not part of the course when it was first taught, but they have been added by us as a guide for the reader, and we do plan to incorporate them in subsequent presentations of the material. We actively solicit feedback from readers of these notes. They are meant to be unpolished, yet, hopefully, transmit substantial material which is of interest to Physicists.

Henry D. I. Abarbanel

M. I. Rabinovich

M. M. Sushchik

January, 1999 


\section{Contents}

Preface

1 Introduction 1

2 Nonlinear Oscillator without Dissipation 6

3 Equilibrium States of a Nonlinear Oscillator with Dissipation 11

4 Oscillations in Systems with Nonlinear Dissipation-Generators 17

5 The Van der Pol Generator 22

6 The Poincaré Map 27

7 Slow and Fust Motions in Systems with One Degree of Freedom 33

8 Forced Nonlinear Oscillators: Linear and Nonlinear Resonances 38

9 Forced Generator: Synchronization 45

10 Competition of Modes 51

11 Poincaré Indices and Bifurcations of Equilibrium States

12 Resonance Interactions between Oscillators 62

13 Solitons 69

14 Steady Propazgation of Shock Waves $\quad 80$

15 Formation of Sthock Waves 86

16 Solitons. Shock Waves. Wave Interaction. The Spectral Approach 89

17 Weak Turbulence. Random Phase Approximation 95

18 Regular Patterns in Dissipative Media 100

19 Deterministic Chros. Qualitative Description 104

20 Description of a Circuit with Chaos. Chaos in Maps 111

21 Bifurcations of Periodic Motions. Period Doubling 116

22 Controlled Nonlinear Oscillator. Intermittency 122

23 Scenarios of the Onset of Chaos. Chaos through Quasi-Periodicity 132

24 Characteristics of Chaos. Experimental Observation of Chaos 139

24.1 Fractal Dimension . . . . . . . . . . . . . 140

24.2 Lyapunov Exponents . . . . . . . . . . . 141 
25 Multidimensional Chaos. Discrete Ginzburg-Landau Model 147

26 Problems to Accompany the Lectures 151

26.1 Lecture One . . . . . . . . . . . . . . . . 151

26.2 Lecture Two . . . . . . . . . . . . . . . . 151

26.3 Lecture Three . . . . . . . . . . . . . . . . . . 152

26.4 Lecture Four . . . . . . . . . . . . . . . . . . . . . 152

26.5 Lecture Five . . . . . . . . . . . . . . . . . . 153

26.6 Lecture Six . . . . . . . . . . . . . . . . 153

26.7 Lecture Seven . . . . . . . . . . . . . . . 154

26.8 Lecture Eight . . . . . . . . . . . . . . . . . . . . . 154

26.9 Lecture Nine . . . . . . . . . . . . . . . . . . 154

26.10 Lecture Ten . . . . . . . . . . . . . . 154

26.11 Lecture Eleven . . . . . . . . . . . . . . . . 155

26.12 Lecture Twelve . . . . . . . . . . . . . . . . . . 155

26.13 Lecture Thirteen . . . . . . . . . . . . . . . . . . 155

26.14 Lecture Fourteen . . . . . . . . . . . . . . . . . . 155

26.15 Lecture Fifteen . . . . . . . . . . . . . . . . 156

26.16 Lecture Sixteen . . . . . . . . . . . . . . . . 156

26.17 Lecture Seventeen . . . . . . . . . . . . . . . 156

26.18 Lecture Eighteen . . . . . . . . . . . . . . . . 156

26.19 Lecture Nineteen . . . . . . . . . . . . . . . 157

26.20 Lecture Twenty . . . . . . . . . . . . . . . . 157

26.21 Lecture Twenty-one . . . . . . . . . . . . . . 157

26.22 Lecture Twenty-two . . . . . . . . . . . . . . . 157

26.23 Lecture Twenty-three . . . . . . . . . . . . . . 158

26.24 Lecture Twenty-four . . . . . . . . . . . . . . 158

26.25 Lecture Twenty-five . . . . . . . . . . . . . . . . 158 